\title{
Methionine and Choline Deficient Diet-induced Non-Alcoholic Steatohepatitis in Rats: Role of Melatonin
}

\author{
Mohamed M. Amin, Rania F. Ahmed*, Dalia O. Saleh \\ Department of Pharmacology, Medical division, National Research Centre, (ID: 60014618), Dokki, 12622, Giza, Egypt.
}

\begin{tabular}{lll}
\hline ARTICLE INFO & & ABSTRACT \\
\cline { 3 - 4 } $\begin{array}{l}\text { Article history: } \\
\text { Received on: } 02 / 06 / 2017 \\
\text { Accepted on: } 15 / 07 / 2017 \\
\text { Available online: } 30 / 09 / 2017\end{array}$ & $\begin{array}{l}\text { Objective: The present study aimed to evaluate the neuro-protective and hepato-protective activity of melatonin } \\
\text { (MLN) on non-alcoholic steatohepatitis (NASH) in albino rats induced by methionine and choline deficient } \\
\text { (MCD) diet. } \\
\text { Mey words: } \\
\text { Melatonin, Non-alcoholic } \\
\text { steatohepatitis, methionine } \\
\text { and choline deficient diet. }\end{array}$ & $\begin{array}{l}\text { Twenty-four hours after the last dose of the MLN behavioral test, namely activity cage test was performed and } \\
\text { the activity counts were recorded. Serum AST, ALT, ALP, GGT, total/direct bilirubin and albumin were valued } \\
\text { to assess liver function. Moreover, hepatic interleukin-6 (IL-6) as well as nuclear factor- } \mathrm{k} \beta \text { (NF-k } \beta \text { ) were } \\
\text { determined. Besides, brain biomarkers viz. ammonia, nitric oxide and brain-derived neurotrophic factor (BDNF) } \\
\text { were measured which are reliable indices to assess brain damage. } \\
\text { Results: MLN succeeded in suppression of NASH rats' locomotor activity. Besides; it improved all biochemical } \\
\text { parameters and histopathological as well as proliferating cell nuclear antigen (PCNA) immunohistochemical } \\
\text { profiles of liver and brain. } \\
\text { Conclusions: These results afford new intuition into the possible molecular mechanisms by which MLN faces } \\
\text { steatohepatitis disorder, via modulation of several factors participating in the progression of this disease. }\end{array}$ \\
\hline
\end{tabular}

\section{INTRODUCTION}

Patients with fatty liver have been projected to be more susceptible to developing cirrhosis, steatosis with inflammation leading to the progress of various nonalcoholic fatty liver disease (NAFLD) that could eventually initiate hepatocellular carcinoma (Sass et al., 2005). Nonalcoholic steatohepatitis (NASH) is a more severe medical case that develops in a subset of patients of NAFLD (Takaki et al., 2014). Although the exact mechanisms remain unclear; NASH is progressed by accumulation of lipid

\footnotetext{
* Corresponding Author

Dr. Rania F. Ahmed, Postal Address: Department of Pharmacology, National Research Centre, (ID: 60014618), Dokki, 12622, Giza, Egypt. E-mail:dr_rania_fouad@yahoo.com;dr.rania.fouad@gmail.com Mobile phone: +201001428874
}

droplets in the liver parenchymal cells leading to enlargement of these cells, which in turn may possibly affect the flow of blood through the hepatic sinusoids and sequentially may worsen hepatic injury by scanting centrilobular regions of oxygen and nutrients(Tanaka et al., 2012). However, numerous influences also may contribute to the change of blood stream through the hepatic microcirculatory including stimulation of Kupffer cells with discharge of vesicular intermediates reactive oxygen species (ROS), nitric oxide (NOx), prostanoids as well as proinflammatory cytokines viz., tumor necrosis factor- $\alpha$ (TNF- $\alpha$ ), interleukin (IL)$1 \beta$, alterations of the endothelial cells, stimulation and narrowing of the peri-sinusoidal stellate cells, and precipitation of collagen and other extracellular proteins in hepatocytes (McCuskey et al., 2004) leading to the development from steatosis to steatohepatitis (Nagaya et al., 2010; Neuschwander-Tetri, 2010; Tilg and Moschen, 2010). 
Diet scarce in essential amino acids such as methionine and choline is a famous model for inducing NASH (Brunt, 2005). Methionine and choline deficient (MCD) diet lacks two constituents, which are critical factors for hepatic $\beta$-oxidation (Diehl, 2005). The testified mechanisms of MCD diet in the induction of NASH may occur through interference of phosphatidylcholine synthesis initiated by methionine and choline deficiency with increase in oxidative stress, fibrogenesis and elevation in the levels of proinflammatory molecules such as interleukin 6 (IL-6). Also, MCD diet leads to triggering of nuclear factor-k $\beta(\mathrm{NF}-\mathrm{k} \beta)$ as a significant relationship between oxidative stress, inflammation and hepatic fibrogenesis (Dela Pena et al., 2005).It was suggested that hepatocyte injury is often correlated with elevated levels of proliferating cell nuclear antigen (PCNA); (Itagaki et al., 2013) which is related to the post-replication repair pathway after DNA damage (Lehmann,Fuchs, 2006). Brainderived neurotrophic factor (BDNF) is a neurotrophin growth factor; usually considered as a driving force behind neuroplasticity and proved to be involved in cognition, neurogenesis and neurodegeneration (Papaleo et al., 2011).

Melatonin (MLN) is a neuron hormone produced in and excreted from the pineal gland during night (Reppert et al., 1994). Alongside to its neuroendocrine utilities; it also exerts psychotropic effects in rats including; sedative, analgesic, anticonvulsant and anxiolytic effects (Sugden, 1983).It guards cellular DNA and membrane lipids from oxidative damage; also, antagonizes oxidative intermediaries thus preventingneuroinflammation (Maldonado et al., 2007, Reiter et al., 2002).

This study aimed to investigate the probable potential role of MLN as a neuro-protective and hepato-protective natural supplement in modulation of enzymatic biomarkers, inflammatory cytokines and cell proliferative mechanisms in MCD induced $\mathrm{NASH}$ in rats, as a future new treatment target for this multipathological disease.

\section{MATERIAL AND METHODS}

\section{Drugs and Chemicals}

Melatonin (MLN)(Sigma-Aldrich Co. St Louis, MO, USA). MLN was administered orally after being freshly suspended in distilled water.

\section{Animals}

Male Wistar rats weighing 70-80 g; obtained from the National Research Centre (NRC, Dokki, Giza, Egypt) Upon arrival, the animals were kept in a quiet place, housed eight per cage and acclimatized to a colony room with controlled ambient temperature $\left(22 \pm 1{ }^{\circ} \mathrm{C}\right)$, humidity $(50 \pm 10 \%)$ and a 12 hour natural light/dark cycle. They were fed a standard diet, water was provided and they were acclimated for 7 days before entry into the subsequent study. They were allowed free access to water and food throughout the period of investigation. The experiments were performed with 8 animals per treatment group according to a randomized schedule.

\section{Ethics Statement}

This study was performed in according to recommendations in the Guide for the Care and Use of Laboratory Animals of the National Institutes of Health (NIH No. 85:23 revised 1985). All surgeries were accomplished under deep sodium pentobarbital anesthesia to minimize suffering.

\section{Experimental Design}

Rats were divided into 3 main groups $(n=8)$, group (1): Normal control group receiving normal pellet diet for 2 months. Groups (2,3) were administered MCD diet (Dyets, Bethlehem, PA, USA) for 2 months(Amini et al., 2011)then one of those groups was used as positive control and the other group was administered MLN (10 mg/ kg p.o) for the last 14 consecutive days (Pan et al., 2006), concomitantly animals in both the normal and the positive control groups were administered daily distilled water ingestions ( $5 \mathrm{ml} / \mathrm{kg}$ p.o). The MCD diet was continued in both groups $(2,3)$ throughout the whole 14 days.

\section{Assessment of locomotor activity}

The activity cage test was performed using a grid-floor detecting activity cage device (Model No. 7430, Ugo-Basile, Italy). Each rat was placed $5 \mathrm{~min}$ in the cage and the locomotor activity was assessed as the total animal activity count during the 5 min (Yang et al., 2003).

\section{Collection of Serum Samples for Analysis}

Blood was collected from the retro orbital plexus of veins under sodium pentobarbital anesthesia and was centrifuged $\left(700 \times \mathrm{g}, 4^{\circ} \mathrm{C}, 20 \mathrm{~min}\right)$ to separate the serum to estimate liver enzymes (AST and ALT) and (GGT, ALP and totalldirect bilirubin) using spectrophotometric colorimetric reagent kits (QCA, Amposta, Spain) and (XpressBio, Thurmont, USA) respectively.

\section{Tissue Extracts}

After serum collection rats were killed by decapitation; livers and brains were separated out, washed, weighed and homogenized in PBS (10\%) for the estimation of the following parameters.

\section{Liver parameters}

ELISA kits were used in the estimation of Interlukin-6 (IBL, Minnesota, USA) and NF-k $\beta$ (EIA ab, Wuhan, China).

\section{Brain parameters}

ELISA kits were used in the estimation of ammonia (Abnova, Taipei, Taiwan), brain derived neurotrophic factor (BDNF) (Kamiya, Seattle, USA) and Nitric Oxide (Stressgen, Ann Arbor, USA).

\section{Histopathological examination}

Autopsy samples from the liver and brain were fixed in $10 \%$ formalin saline for twenty-four hours. Then washed by tap 
water followed by serial dilutions of alcohol (methyl, ethyl and absolute ethyl)for dehydration. Specimens were cleared in xylene and embedded in paraffin at $56{ }^{\circ} \mathrm{C}$ in hot air oven for twenty-four hours. Paraffin beeswax tissue blocks were prepared for sectioning at 4 microns thickness by sledge microtome. Tissue sections were then put on glass slides, deparaffinized, stained by hematoxylin \& eosin stain for routine examination through the light microscope.

\section{Proliferating cell nuclear antigen Immunohistochemistry examination}

All solutions according to manufacturer's recommendation were prepared, and serial unstained paraffin slides from histology were obtained and paraffin sections cleared and rehydrated according to the following steps:

\begin{tabular}{ccc}
\hline Step No. & Reagent & Time (minutes) \\
\hline 1 & Xylene & 5 \\
2 & Xylene & 5 \\
3 & $100 \%$ EtOH & 2 \\
4 & $100 \%$ EtOH & 2 \\
5 & $3 \% \mathrm{H}_{2} \mathrm{O}_{2}$ in $\mathrm{MeOH}$ & 10 \\
6 & $100 \% \mathrm{EtOH}$ & 1 \\
7 & $100 \% \mathrm{EtOH}$ & 3 \\
8 & $100 \%$ EtOH & 1 \\
9 & Water & 1 \\
\hline
\end{tabular}

Then antigen retrieval using citrate buffer in a steamer at $95 \mathrm{C}^{\circ}$ for 30 minutes were performed and the slides were washed with buffer for $\leq 5$ minutes. After that, slides were loaded on mouse monoclonal anti-PCNA/anti-D2-40 antibody PC 10 Dako auto-stainer (Dako, Santa Barbara, CA) for 15 minutes and rinsed. After that, slides were incubated with the first primary anti-rabbit IgG for 30 minutes and rinsed twice, then incubated with the secondary antibody (Mach 2 HRP polymer) for 30 minutes and rinsed twice. Diaminobenzidinetetrahydrochloride was used as a chromogen for four minutes and rinsed twice. Then, slides were washed with PBS and counterstained with hematoxylin (1 minute) and washed with water and allowed to air to dry for 2 hours. After that, slides were cover-slipped using aqueous mounting media and scanned using Aperio CS scanner (Aperio, Vista, CA) (CampbellThompson et al., 2009).

\section{Statistical Analysis}

Statistical analysis was performed by non-parametric $\mathrm{K}$ independent samples Kruskal-Wallis test followed by Dunn's multiple comparisons test for the activity cage test and one-way ANOVA followed by LSD and Tukey HSD post hoc multiple comparisons test for the other parameters. Data was expressed as mean \pm SEM. Significances were expressed at $p<0.05$.

\section{RESULTS}

\section{Assessment of the relative Liver weight (LW) and Body weight (BW)}

Rats fed with MCD diet for 8 weeks showed a decrease in the $\mathrm{BW}$ and an increase in the relative $\mathrm{LW}$ as compared to the normal control group. Oral treatment of MCD-diet fed rats with
MLN (10 mg/kg/day) for the 14 consecutive days showed restoration of the $\mathrm{BW}$ and the relative $\mathrm{LW}$ as compared to MCD diet-induced NASH group (Table 1).

Table 1: Effect of MLN on body weight, liver weight and relative liver in MCD diet-induced NASH in rats.

\begin{tabular}{cccc}
\hline & BW & LW & Relative LW \\
\hline Normal & $117.2 \pm 2.4$ & $3.22 \pm 0.25$ & $2.75 \pm 0.21$ \\
NASH & $87.2 \pm 2.99^{*}$ & $3.52 \pm 0.18$ & $4.36 \pm 0.3 *$ \\
Melatonin & $110.6 \pm 5.59^{\circledR}$ & $3.93 \pm 0.13$ & $3.58 \pm 0.13 @$ \\
\hline *Significantly different from normal control; ${ }^{\circledR}$ significantly different from the \\
NASH control at P $<0.05$.
\end{tabular}

\section{Assessment of the locomotor activity}

Rats fed with MCD diet for 8 weeks showed a prominent increase in the activity count when placed in the activity cage (273.6 $\pm 9.35 v s$. $169.8 \pm 5.47 \mathrm{count} / 5 \mathrm{~min}, P<0.05)$ by comparison with the normal control group. Oral ingestion of MLN $(10 \mathrm{mg} / \mathrm{kg} /$ day) for the 14 consecutive days showed decrease in the activity count $(180.3 \pm 11.95 v s .273 .6 \pm 9.35$ count $/ 5 \mathrm{~min}, P<0.05)$ as compared to MCD diet-induced NASH group (Figure 1).

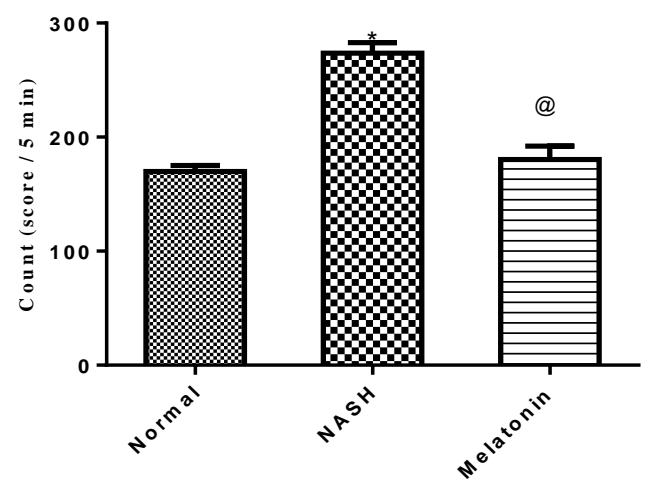

Fig. 1: Effect of MLN on the activity cage in MCD diet-induced NASH in rats * Significance from normal control; @ Significance from the NASH control; P $<0.05$.

\section{Assessment of the hepatic function}

MCD diet resulted in a marked elevation in the serum liver function parameters viz. serum levels of ALT, AST, ALP, GGT, total and direct bilirubin by comparison with the normal control group. Furthermore, rats fed with MCD diet showed a decrease in the serum albumin level. Oral treatment of MCD-diet fed rats with MLN (10 mg/kg/day) for the 14 consecutive days showed restoration of the serum levels of ALT, AST, ALP, GGT, albumin, total and direct bilirubin (Table 2).

Table 2: Effect of MLN on serum hepatic function parameters in MCD dietinduced NASH in rats.

\begin{tabular}{lccc}
\hline & Normal & NASH & $\begin{array}{c}\text { MLN } \\
(\mathbf{1 0 ~ m g / k g})\end{array}$ \\
\hline AST (U/L) & $27.0 \pm 1.0$ & $134.9 \pm 2.9^{*}$ & $37.3 \pm 1.22^{@}$ \\
ALT (U/L) & $25.3 \pm 0.99$ & $125.9 \pm 2.48^{*}$ & $34.3 \pm 1.22^{@}$ \\
ALP (U/L) & $54.4 \pm 2.99$ & $369.4 \pm 20.18^{*}$ & $83.1 \pm 2.01^{@}$ \\
GGT (U/L) & $16.7 \pm 0.99$ & $154.2 \pm 3.08^{*}$ & $52.7 \pm 1.24^{@}$ \\
Total Bilirubin (mg/dl) & $0.548 \pm 0.024$ & $2.005 \pm 0.046^{*}$ & $0.719 \pm 0.017^{@}$ \\
Direct Bilirubin (mg/dl) & $0.121 \pm 0.003$ & $0.573 \pm 0.033^{*}$ & $0.189 \pm 0.003^{@}$ \\
Albumin (g/dl) & $4.32 \pm 0.066$ & $2.58 \pm 0.066^{*}$ & $3.46 \pm 0.018^{\circledR}$ \\
\hline
\end{tabular}

* Significantly different from normal control; ${ }^{@}$ significantly different from the NASH control at $\mathrm{P}<0.05$. 


\section{Assessment of the hepatic cytokine (IL-6) and its modulator (NF-k $\beta$ )}

Rats fed with MCD diet for 8 weeks showed a marked increase in the hepatic IL-6 and NF-k $\beta(46.31 \pm 1.95$ vs. $6.8 \pm 0.37$ $\mathrm{pg} / \mathrm{g}$ tissue and $4.51 \pm 0.21 \mathrm{vs} .0 .56 \pm 0.02 \mathrm{ng} / \mathrm{g}$ tissue, $P<0.05)$ respectively as compared to the normal control. Oral treatment of MCD-diet fed rats with MLN (10 mg/kg/day) for the 14 consecutive days showed a decrease in the hepatic IL- 6 content (17.5 $\pm 0.84 v s .46 .31 \pm 1.95 \mathrm{pg} / \mathrm{g}$ tissue, $P<0.05)$, similarly, treatment with MLN attenuated the hepatic NF-k $\beta$ content (1.34 $\pm 0.08 v s .4 .51 \pm 0.21 \mathrm{ng} / \mathrm{g}$ tissue, $P<0.05)$ as compared to MCD diet-induced NASH group (Figure 2).

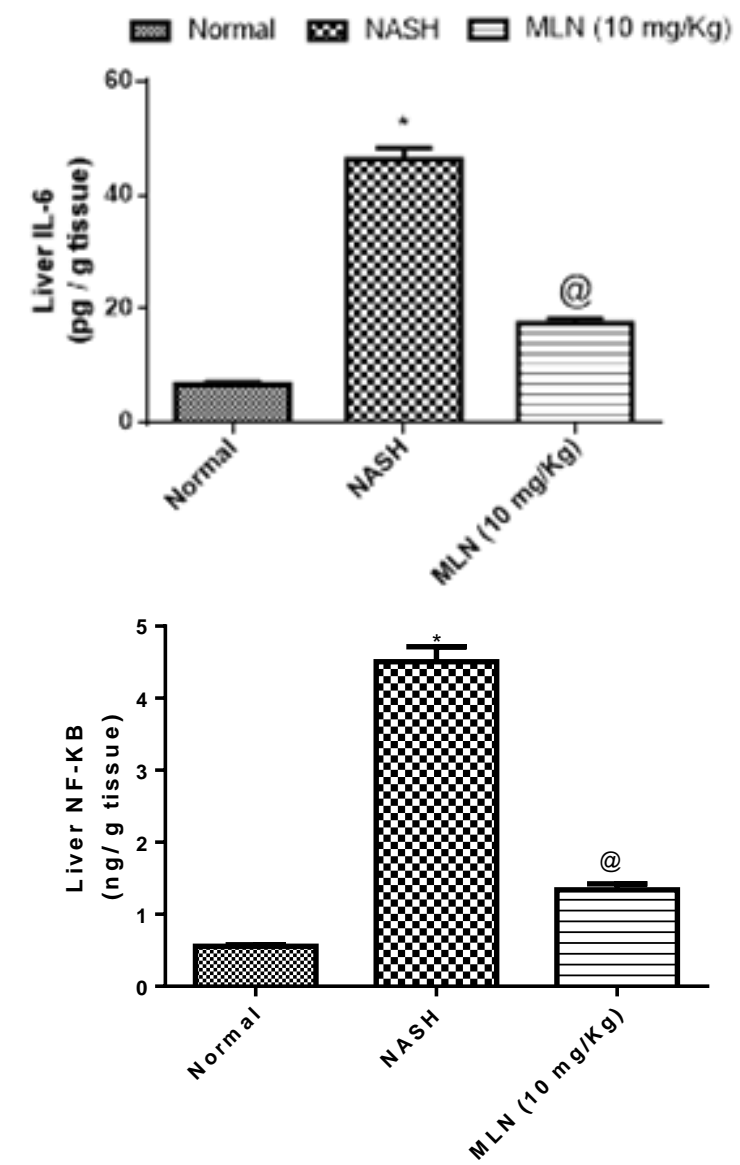

Fig. 2: Effect of MLN on hepatic contents of IL- 6 and NF- $\kappa \beta$ in MCD dietinduced NASH in rats. * Significance from normal control; ${ }^{\circledR}$ Significancefrom the NASH control; $\mathrm{P}<0.05$.

Assessment of the brain contents of ammonia, NOx and BDNF

Rats fed with MCD diet for 8 weeks showed a marked increase in the brain contents of ammonia and NOx (1.84 \pm 0.04 vs. $0.25 \pm 0.007 \mu \mathrm{g} / \mathrm{g}$ tissue, $P<0.05)$ and $(19.14 \pm 0.44$ vs. $3.44 \pm$ $0.2 \mu \mathrm{mol} / \mathrm{g}$ tissue, $P<0.05)$, respectively, by comparison with the normal control group. In addition, MCD diet fed rats showed a prominent decrease in the brain BDNF content $(0.26 \pm 0.013$ vs. 1.5 $\pm 0.064 \mathrm{ng} / \mathrm{g}$ tissue, $P<0.05)$ by comparison with the normal control group. Ingesting MLN (10 mg/kg/dayp.o) for 14 consecutive days attenuated the increase in brain contents of ammonia and NOx $(0.66 \pm 0.03 v s .1 .84 \pm 0.04 \mu \mathrm{g} / \mathrm{g}$ tissue, $P<0.05)$ and $(6.29 \pm 0.2 v s .19 .14 \pm 0.44 \mu \mathrm{mol} / \mathrm{g}$ tissue, $P<0.05)$, respectively. Similarly, treatment with MLN increased the BDNF content $(0.74 \pm 0.014 v s .0 .26 \pm 0.013 \mathrm{ng} / \mathrm{g}$ tissue, $P<0.05)$ as compared to MCD diet-induced NASH group (Figure 3).
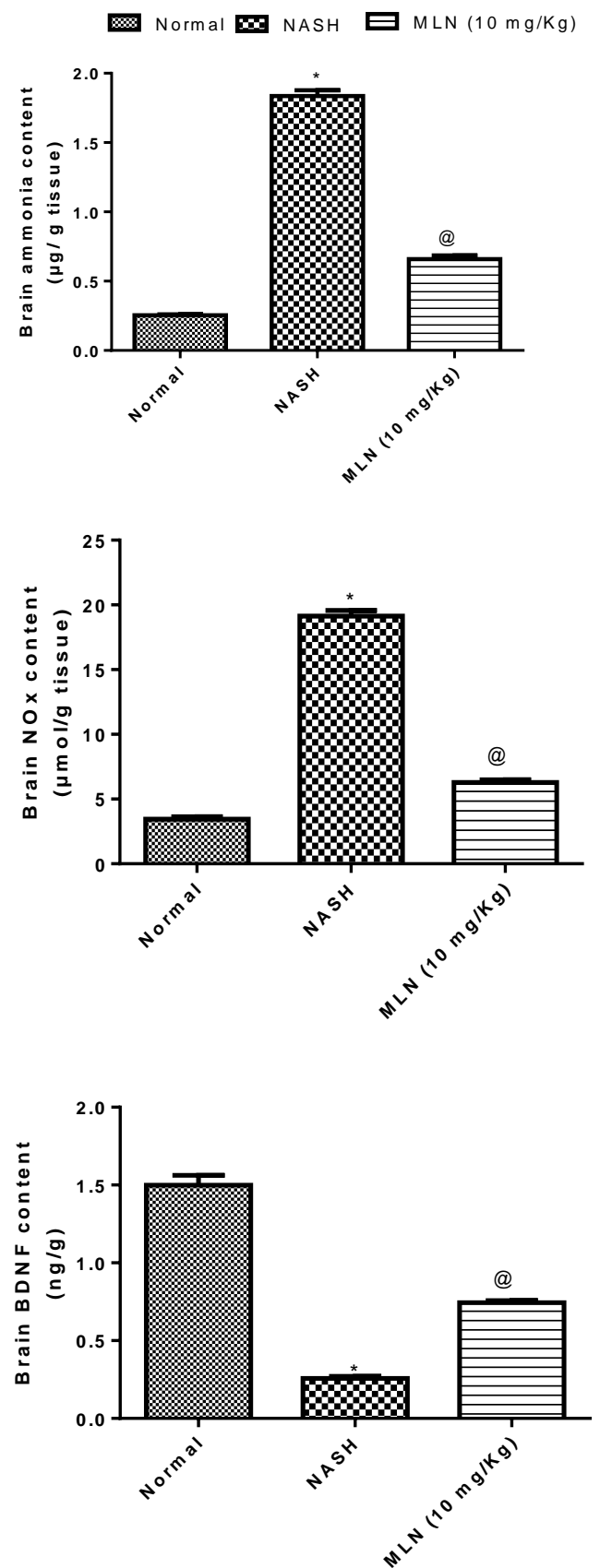

Fig. 3: Effect of MLN on brain contents of ammonia, nitric oxide and brain derived neurotrophic factor in MCD diet-induced NASH in rats. * Significance from normal control; ${ }^{\circledR}$ Significancefrom the NASH control; $\mathrm{P}<0.05$.

\section{Assessment of Proliferating Cell Nuclear Antigen immunohistochemically}

PCNA immunostaining reaction was confined to the nuclei. The reaction product was present in different patterns from a faint to strong densely stained nuclear granular reaction filling the whole nucleus. Sections for the control reaction gave a 
negative PCNA stain. Examination of liver sections in MCD dietinduced NASH showed densely stained nuclei. However, liver sections isolated from MLN treated groups only few nuclei were stained (Figure. 4a, Table 3a).

Table 3a: Effect of MLN on the severity of PCNA immunopathological reactions in brain and liver in MCD diet-induced NASH in rats.

\begin{tabular}{|c|c|c|c|}
\hline & Normal & NASH & MLN (10 mg/kg) \\
\hline Brain & - & +++ & ++ \\
\hline Liver & - & + & - \\
\hline
\end{tabular}
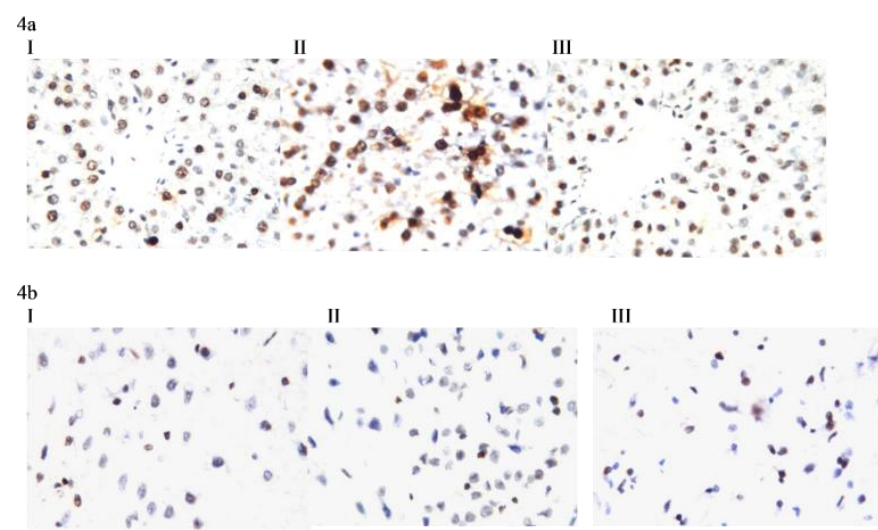

Fig. 4: Effect of MLN on the liver (a) and the brain (b) of PCNA immunopathological reactions in brain and liver in MCD diet-induced NASH in rats. (4aI) Liver sections isolated from control group showing a negative PCNA stain. (4aII)Liver sections isolated from NASH rats showed densely stained nuclei. (4aIII) Liver sections isolated from MLN treated groups only few nuclei were stained. (4bI) Brain sections isolated from control group showing a negative PCNA stain. (4bII)Brain sections isolated from NASH rats showed densely stained nuclei. (4bIII) Brain sections isolated from MLN treated groups only few nuclei were stained

Examination of brain sections from the control reaction gave a negative PCNA stain. MCD diet-induced NASH showed mild stained nuclei. However, brain sections isolated from MLN treated groups showed negative PCNA stain (Figure. 4b, Table 3a).

\section{Assessment of the histopathological changes of the liver and the brain}

Hepatic tissues isolated from normal rats showed normal histological structure of the central vein and surrounding hepatocytes in the parenchyma (Figure 5aI). However, fatty changes were observed in the hepatocytes all over the hepatic parenchyma of tissue isolated from MCD-diet fed rats (Figure 5aII). On the other hand, fatty changes were observed in only few individual hepatocytes in the parenchyma of the hepatic tissue isolated from MCD-diet fed rats treated with MLN (10mg/ kg) (Figure 5aIII; Table 3b).

Brain tissues isolated from normal rats showed normal histological structure of the meninges with underlying cerebral cortex, hippocampus (Figure 5bI), striatum in the cerebrum and cerebellum (Figure 5bII). However, the cerebrum of the brain tissues isolated from MCD-diet fed rats showed congestion in the blood vessels (Figure 5bIII), associated with pyknosis, degeneration and atrophy in the neurons of the hippocampus
(Figure 5bIV). There was eosinophilic plagues formation in the striatum (Figure 5bV). On the other hand, there were focal eosinophilic plagues in the striatum of the brain tissue isolated from MCD-diet fed rats treated with MLN (10mg/ kg) (Figure 5bVI; Table 3b).

Table 3b: Effect of MLN on the severity of histopathological changes in brain and liver in MCD diet-induced NASH in rats.

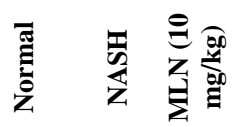

\begin{tabular}{ccccccc}
\hline \multirow{2}{*}{ Brain } & $\bullet$ & Pyknosis of hippocampus neurons & - & +++ & + \\
& $\bullet$ & Plagues formation in striatum & - & +++ & + \\
\hline Liver & $\bullet$ & Fatty changes & & - & +++ & + \\
\hline Non & + & Mild $\quad++$ & Moderate $\quad+++$ Severe & &
\end{tabular}
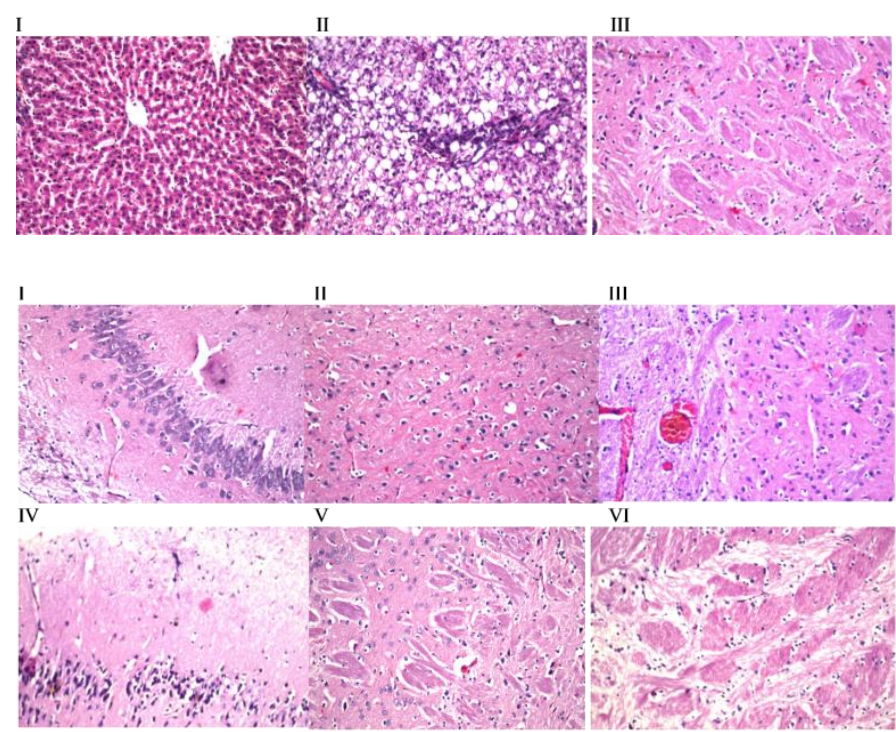

Fig. 5: Effect of MLN on the liver (a) and the brain (b) histopathological changes in MCD diet-induced NASH in rats. (5aI) Hepatic tissues isolated from normal rats showing no histopathological change. (5aII) Hepatic tissue isolated from NASH rats showing fatty changes all over the hepatocytes. (5aIII) Hepatic tissue isolated from NASH rats treated with MLN $(10 \mathrm{mg} / \mathrm{kg})$ where fatty changes were observed in only few individual hepatocytes. (5bI, II) Brain tissues isolated from normal rats showing no histopathological alteration of the meninges with underlying cerebral cortex, hippocampus (5bI) and striatum in the cerebrum and cerebellum (5bII). (5bIII-V) Brain tissues isolated from NASH rats showing congestion in the blood vessels (5bIII), associated with pyknosis, degeneration and atrophy in the neurons of the hippocampus (5bIV), with eosinophilic plagues formation in the striatum (Figure 5bV). (5bVI) Brain tissue isolated from NASH rats treated with MLN $(10 \mathrm{mg} / \mathrm{kg})$ showing only few histopathological alterations and focal eosinophilic plagues in the striatum of the brain tissue.

\section{DISCUSSION}

Mechanisms underlying the progression from a normal liver to NASH have been discussed in several experimental models(Baumgardner et al., 2008).Methionine choline-deficient diet is a frequently used nutritional model of NASH, causing histological steatohepatitis that is very similar to human NASH. Feeding on MCD diet induces hepatic inflammation, steatosis, and fibrosis (Leclercq et al., 2000; Saleh et al., 2017; Syn et al., 2011). 
Previously in our lab; we investigated the beneficial outcomes of using coenzyme Q10; which is a well-known antioxidant with established hepato-protective abilities (Amin et al., 2014) to counteract both hepatic and neuronal side effects accompanying MCD-induced NASH and the results were really promising (Saleh et al., 2017).In the present study, we wanted to try using a well-known neuroprotective agent namely melatonin (MLN) (Pandi-Perumal et al., 2006) to investigate its efficacy on the same model as modulator of enzymatic biomarkers, inflammatory cytokines and cell proliferative mechanisms. Former investigators reported that MLN has a significant impact in many models of hepatic disorders specially NASH and functions as antiinflammatory and anti-apoptotic agent in liver yet; its full mechanism of action has not been deeply elucidated (Cichoz-Lach et al., 2010; Tahan et al., 2009).

Similar to the previous study in our lab; MCD diet showed a significant decrease in BW and increase in the relative LW. Serum levels of ALT, AST, ALP, GGT, total and direct bilirubin were markedly increased, while serum levels of albumin were decreased suggesting liver dysfunction and bile duct injury. Moreover; MCD diet resulted in significant increase in aggressiveness represented by hyper locomotor activity as well as significant elevation in the brain NOx and ammonia levels. Additionally, our results revealed that MCD-induced NASH in rats decreased the brain levels of BDNF.

These findings are in agreement with former investigators who stated that the decline in the major methyl donor methionine caused by NASH results in folate deficiency and consequently marked aggressive behavior as well as neurodegeneration (Chan et al., 2008). Moreover; it was reported that deficiency in methionine or choline induced significant increase in NOx concentration in all brain regions (Veskovic et al., 2015). Furthermore; it was previously designated that BDNF modulates neuronal survival and thus affects neurogenesis (Tosini et al., 2012). Histologically, fatty changes along with tissue injury and inflammation were observed. The cerebrum of the brain tissues isolated from MCD-diet fed rats showed congestion in the blood vessels, pyknosis, degeneration and atrophy in the neurons of the hippocampus. These findings are in agreement with previous investigations in our lab as well as formers investigators' results (Itagaki et al., 2013; Saleh et al., 2017).

Proliferating cell nuclear antigen, as a marker of liver and brain tissue DNA damage has been investigated immunohistochemically. These immunohistochemical investigations were carried out in order to improve our understanding of histopatholiogical changes. Previous researchers stated that tissue injury is often correlated with elevated levels of PCNA and that the number of PCNA-positive hepatocytes increased significantly in mice fed MCD diet. (Itagaki et al., 2013). Similar effects were obtained in our research. Oral treatment of MCD diet fed rats with MLN (10 mg/kg; p.o.) for 14 days markedly improved enzymatic parameters viz., the serum levels ALT, AST, ALP, GGT, albumin, total and direct bilirubin. These findings were in accordance with another studies which showed the valuable outcome of MLN treatment on plasma liver enzymes levels in patients with NASH (Gonciarz et al., 2012) and against thioacetamide-induced liver fibrosis in rats (Czechowska et al., 2015).

Furthermore, oral treatment of MCD diet fed rats with MLN $(10 \mathrm{mg} / \mathrm{kg})$ for 14 days reduced the level of proinflammatory cytokines IL-6 as well as its modulator NF-k $\beta$ which is the factor of transcription associated with increased expression of proinflammatory genes. One of the principal indicators of liver fibrosis is the discharge of proinflammatory cytokines by Kupffer cells and enhanced exponentiation of hepatic stellate cells (Tsukamoto, 1999). Development of fibrogenesis results in amplified production of collagen, and augmented release of NF$\kappa \beta$. It has been revealed that MLN in addition to decreasing the accumulation of collagen; it ameliorated hepatic inflammation through inhibiting NF- $\kappa \beta$ translocation to the nucleus and binding to DNA (Czechowska et al., 2015).

Our findings revealed that MLN reversed NASH induced aggressive behavior. Moreover; it reduced brain ammonia and NOx levels. These results are in rhyme with previous researches; where reduction of aggressive behavior and hyper locomotor activity by MLN as well as neuroprotective properties and amelioration of brain oxidative stress have been previously reported in other psychotic conditions (Bazrgar et al., 2015, Souza et al., 2014). The neuroprotective role of MLN is attributed to its ability to ameliorate radical formation through its anti-excitatory and anti-inflammatory effects (Pandi-Perumal et al., 2006).

Our results revealed that MLN significantly increased the BDNF level. Previous investigators reported that MLN significantly prevented the chronic administration of high doses of dexamethasone induced reduction in the expression of BDNF (Ruksee et al., 2014, Tongjaroenbuangam et al., 2013). MLN also increased the expression of BDNF in other models of neurotoxicity and neurodegenerative disorders (Bavithra et al., 2015; Rudnitskaya et al., 2015; Zhang et al., 2013). On the histopathological level; fatty changes were observed in only few individual hepatocytes in the parenchyma of the hepatic tissue isolated from MCD-diet fed rats treated with MLN and there was a significant improvement in the histopathological changes in the brain tissue isolated from MCD-diet fed rats treated with MLN. Furthermore, MLN treated group showed beneficial effects represented by only few stained nuclei with PCNA in the liver and negative stain on the brain indicating tissue DNA preservation ability.

\section{CONCLUSION}

Our study afford new intuition into the probable molecular pathways by which MLN confronts steatohepatitis disorder, via modulation of several factors participating in the progression of this disease. Thus, from all the previous findings we can conclude that MLN has a hepato-protective and neuroprotective role in modulation of enzymatic biomarkers, inflammatory cytokines and cell proliferative mechanisms in MCD 
induced NASH in rats, as a future new treatment target for this multi-pathological disease.

\section{ACKNOWLEDGMENTS}

We would like to thank Prof. Adel Bekir, Pathology Department, Faculty of Veterinary Medicine, Cairo University, Egypt for assessment of histopathology and immunohistochemistry.

\section{Financial support and sponsorship: Nil.}

Conflict of Interests: There are no conflicts of interest.

\section{REFERENCES}

Amin MM, Asaad GF, Abdel Salam RM, El-Abhar HS, Arbid MS. Novel CoQ10 antidiabetic mechanisms underlie its positive effect: modulation of insulin and adiponectine receptors, Tyrosine kinase, PI3K, glucose transporters, sRAGE and visfatin in insulin resistant/diabetic rats. PLoS One, 2014; 9: e89169.

Amini R, Yazdanparast R, Aghazadeh S, Ghaffari SH. Teucrium polium reversed the MCD diet-induced liver injury in rats. Hum Exp Toxicol, 2011; 30: 1303-12.

Baumgardner JN, Shankar K, Hennings L, Badger TM, Ronis MJ. A new model for nonalcoholic steatohepatitis in the rat utilizing total enteral nutrition to overfeed a high-polyunsaturated fat diet. Am J Physiol Gastrointest Liver Physiol, 2008; 294: G27-38.

Bavithra S, Sugantha Priya E, Selvakumar K, Krishnamoorthy G, Arunakaran J. Effect of Melatonin on Glutamate: BDNF Signaling in the Cerebral Cortex of Polychlorinated Biphenyls (PCBs)-Exposed Adult Male Rats. Neurochem Res, 2015; 40: 1858-69.

Bazrgar M, Goudarzi I, Lashkarbolouki T, Elahdadi Salmani M. Melatonin ameliorates oxidative damage induced by maternal lead exposure in rat pups. Physiol Behav, 2015; 151: 178-88.

Brunt EM. Pathology of nonalcoholic steatohepatitis. Hepatol Res, 2005; 33: 68-71.

Campbell-Thompson M, Dixon LR, Wasserfall C, Monroe M, McGuigan JM, Schatz D, Crawford JM, Atkinson MA. Pancreatic adenocarcinoma patients with localised chronic severe pancreatitis show an increased number of single beta cells, without alterations in fractional insulin area. Diabetologia, 2009; 52: 262-70.

Chan A, Tchantchou F, Graves V, Rozen R, Shea TB. Dietary and genetic compromise in folate availability reduces acetylcholine, cognitive performance and increases aggression: critical role of S-adenosyl methionine. J Nutr Health Aging, 2008; 12: 252-61.

Cichoz-Lach H, Celinski K, Konturek PC, Konturek SJ, Slomka M. The effects of L-tryptophan and melatonin on selected biochemical parameters in patients with steatohepatitis. J Physiol Pharmacol, 2010; 61: $577-80$.

Czechowska G, Celinski K, Korolczuk A, Wojcicka G, Dudka J, Bojarska A, Reiter RJ. Protective effects of melatonin against thioacetamide-induced liver fibrosis in rats. J Physiol Pharmacol, 2015; 66: $567-79$

Dela Pena A, Leclercq I, Field J, George J, Jones B, Farrell G. NF-kappaB activation, rather than TNF, mediates hepatic inflammation in a murine dietary model of steatohepatitis. Gastroenterology, 2005; 129: 1663-74.

2005; 33: 138-44

Diehl AM. Lessons from animal models of NASH. Hepatol Res,

Gonciarz M, Gonciarz Z, Bielanski W, Mularczyk A, Konturek PC, Brzozowski T, Konturek SJ. The effects of long-term melatonin treatment on plasma liver enzymes levels and plasma concentrations of lipids and melatonin in patients with nonalcoholic steatohepatitis: a pilot study. J Physiol Pharmacol, 2012; 63: 35-40.
Itagaki H, Shimizu K, Morikawa S, Ogawa K, Ezaki T. Morphological and functional characterization of non-alcoholic fatty liver disease induced by a methionine-choline-deficient diet in C57BL/6 mice. Int J Clin Exp Pathol, 2013; 6: 2683-96.

Leclercq IA, Farrell GC, Field J, Bell DR, Gonzalez FJ, Robertson GR. CYP2E1 and CYP4A as microsomal catalysts of lipid peroxides in murine nonalcoholic steatohepatitis. J Clin Invest, 2000; 105 : 1067-75

Lehmann AR, Fuchs RP. Gaps and forks in DNA replication: Rediscovering old models. DNA Repair (Amst), 2006; 5: 1495-8.

Maldonado MD, Murillo-Cabezas F, Terron MP, Flores LJ, Tan DX, Manchester LC, Reiter RJ. The potential of melatonin in reducing morbidity-mortality after craniocerebral trauma. J Pineal Res, 2007; 42: 111 .

McCuskey RS, Ito Y, Robertson GR, McCuskey MK, Perry M, Farrell GC. Hepatic microvascular dysfunction during evolution of dietary steatohepatitis in mice. Hepatology, 2004; 40: 386-93.

Nagaya T, Tanaka N, Suzuki T, Sano K, Horiuchi A, Komatsu M, Nakajima T, Nishizawa T, Joshita S, Umemura T, Ichijo T, Matsumoto A, Yoshizawa K, Nakayama J, Tanaka E, Aoyama T. Down-regulation of SREBP-1c is associated with the development of burned-out NASH. J Hepatol, 2010; 53: 724-31.

Neuschwander-Tetri BA. Hepatic lipotoxicity and the pathogenesis of nonalcoholic steatohepatitis: the central role of nontriglyceride fatty acid metabolites. Hepatology, 2010; 52: 77488 .

Pan M, Song YL, Xu JM, Gan HZ. Melatonin ameliorates nonalcoholic fatty liver induced by high-fat diet in rats. J Pineal Res, 2006; 41: 79-84.

Pandi-Perumal SR, Srinivasan V, Maestroni GJ, Cardinali DP, Poeggeler B, Hardeland R. Melatonin: Nature's most versatile biological signal? FEBS J, 2006; 273: 2813-38.

Papaleo F, Silverman JL, Aney J, Tian Q, Barkan CL, Chadman KK, Crawley JN. Working memory deficits, increased anxiety-like traits, and seizure susceptibility in BDNF overexpressing mice. Learn Mem, 2011; 18: 534-44.

Reiter RJ, Tan DX, Sainz RM, Mayo JC, Lopez-Burillo S. Melatonin: reducing the toxicity and increasing the efficacy of drugs. J Pharm Pharmacol, 2002; 54: 1299-321.

Reppert SM, Weaver DR, Ebisawa T. Cloning and characterization of a mammalian melatonin receptor that mediates reproductive and circadian responses. Neuron, 1994; 13: 1177-85.

Rudnitskaya EA, Maksimova KY, Muraleva NA, Logvinov SV, Yanshole LV, Kolosova NG, Stefanova NA. Beneficial effects of melatonin in a rat model of sporadic Alzheimer's disease. Biogerontology, 2015; 16: 303-16.

Ruksee N, Tongjaroenbuangam W, Mahanam T, Govitrapong P. Melatonin pretreatment prevented the effect of dexamethasone negative alterations on behavior and hippocampal neurogenesis in the mouse brain. J Steroid Biochem Mol Biol, 2014; 143: 72-80.

Saleh DO, Ahmed RF, Amin MM. Modulatory role of Coenzyme Q10 on methionine and choline deficient diet-induced nonalcoholic steatohepatitis (NASH) in albino rats. Appl Physiol Nutr Metab, 2017; 42: 243-49.

Sass DA, Chang P, Chopra KB. Nonalcoholic fatty liver disease: a clinical review. Dig Dis Sci, 2005; 50: 171-80.

Souza LC, Wilhelm EA, Bortolatto CF, Nogueira CW, Boeira SP, Jesse CR. The protective effect of melatonin against brain oxidative stress and hyperlocomotion in a rat model of mania induced by ouabain. Behav Brain Res, 2014; 271: 316-24.

Sugden D. Psychopharmacological effects of melatonin in mouse and rat. J Pharmacol Exp Ther, 1983; 227: 587-91.

Syn WK, Choi SS, Liaskou E, Karaca GF, Agboola KM, Oo YH, Mi Z, Pereira TA, Zdanowicz M, Malladi P, Chen Y, Moylan C, Jung Y, Bhattacharya SD, Teaberry V, Omenetti A, Abdelmalek MF, Guy CD, Adams DH, Kuo PC, Michelotti GA, Whitington PF, Diehl AM. Osteopontin is induced by hedgehog pathway activation and promotes fibrosis progression in nonalcoholic steatohepatitis. Hepatology, 2011; 53: 106-15. 
Tahan V, Atug O, Akin H, Eren F, Tahan G, Tarcin O, Uzun H, Ozdogan O, Tarcin O, Imeryuz N, Ozguner F, Celikel C, Avsar E, Tozun $\mathrm{N}$. Melatonin ameliorates methionine- and choline-deficient diet-induced nonalcoholic steatohepatitis in rats. J Pineal Res, 2009; 46: 401-7.

Takaki A, Kawai D, Yamamoto K. Molecular mechanisms and new treatment strategies for non-alcoholic steatohepatitis (NASH). Int J Mol Sci, 2014; 15: 7352-79.

Tanaka N, Matsubara T, Krausz KW, Patterson AD, Gonzalez FJ. Disruption of phospholipid and bile acid homeostasis in mice with nonalcoholic steatohepatitis. Hepatology, 2012; 56: 118-29.

Tilg $\mathrm{H}$, Moschen AR. Evolution of inflammation in nonalcoholic fatty liver disease: the multiple parallel hits hypothesis. Hepatology, 2010; 52: 1836-46.

Tongjaroenbuangam W, Ruksee N, Mahanam T, Govitrapong P. Melatonin attenuates dexamethasone-induced spatial memory impairment and dexamethasone-induced reduction of synaptic protein expressions in the mouse brain. Neurochem Int, 2013; 63: 482-91.

Tosini G, Ye K, Iuvone PM. N-acetylserotonin: neuroprotection, neurogenesis, and the sleepy brain. Neuroscientist, 2012; 18: $645-53$.

Tsukamoto H. Cytokine regulation of hepatic stellate cells in liver fibrosis. Alcohol Clin Exp Res, 1999; 23: 911-6.
Veskovic M, Mladenovic D, Jorgacevic B, Stevanovic I, de Luka S, Radosavljevic T. Alpha-lipoic acid affects the oxidative stress in various brain structures in mice with methionine and choline deficiency. Exp Biol Med (Maywood), 2015; 240: 418-25.

Yang PB, Amini B, Swann AC, Dafny N. Strain differences in the behavioral responses of male rats to chronically administered methylphenidate. Brain Res, 2003; 971: 139-52.

Zhang L, Zhang HQ, Liang XY, Zhang HF, Zhang T, Liu FE. Melatonin ameliorates cognitive impairment induced by sleep deprivation in rats: role of oxidative stress, BDNF and CaMKII. Behav Brain Res, 2013; 256: 72-81

\section{How to cite this article:}

Amin MM, Ahmed RF, Saleh DO. Methionine and Choline Deficient Diet-induced Non-Alcoholic Steatohepatitis in Rats: Role of Melatonin on Brain Derived Neurotrophic Factor. J App Pharm Sci, 2017; 7 (09): 012-019. 